\title{
Morphological characterization of Terminalia chebula (Aralu) and their propagation techniques
}

\author{
Niluka Nakandalage ${ }^{* *}$, MA De Silva ${ }^{1}$, HIGK Anuruddi', HLI Priyadarshani², \\ HKMS Kumarasinghe ${ }^{1}$ and S Subasinghe ${ }^{1}$ \\ ${ }^{1}$ Department of Crop Science, Faculty of Agriculture, University of Ruhuna, Mapalana, \\ Kamburupitiya, Sri Lanka. \\ ${ }^{2}$ Medicinal Plant Garden, Pinnaduwa, Galle, Sri Lanka
}

*Email: nilukanakandala@gmail.com

Received : 18.01.2020 ; Revised: 08.05.2021 ; Accepted:10.05.2021

\begin{abstract}
Terminalia chebula (Aralu) is a valuable medicinal plant, which has an amazing power to combat various kinds of ailments. The plant becomes endangered due to its poor natural resurgence, unsustainable harvesting together with over exploitation. The conventional propagation of Terminalia chebula is through seeds and their germination is very low. This study was focused on morphological characterization of Terminalia chebula germplasm and to select suitable vegetative propagation method. A field survey was carried out in Galle and Matara districts, in Southern province of Sri Lanka for germplasm characterization. Ten plants were selected from each district. Information on growing environment, plant, leaf and fruit characters were collected and compared with the herbarium of Royal Botanical Garden. Data were subjected to a cluster analysis and two sample test. In subsequent experiments, grafting, budding and air layering were practiced and they were carried out at the medicinal plant garden, Pinnaduwa, Galle. One-year old healthy rootstocks of Terminalia catappa (kottamba) and Terminalia bellerica (bulu) were used for wedge grafting and patch budding while keeping Terminalia chebula as the scion. Completely randomized design in factorial arrangement was used with 9 replicates. Air layering was carried out using two hormone types together with their three different concentrations including 500,700 and 900 ppm. Randomized complete block design was used with three replicates. Six different categories of Terminalia chebula were identified by cluster analysis. Both Terminalia catappa and Terminalia bellerica rootstocks can be used for vegetative propagation of Aralu. The highest survival percentages of $78 \%$ and $67 \%$ were recorded respectively in wedge grafted Terminalia chebula using Terminalia catappa root stock and patch budding with Terminallia bellerica. Types and concentrations of hormones used were not effective for Terminalia chebula air layering. Different categories of Aralu reported in study provide clues for its existing considerable genetic variability. Chemical compounds present in these six different categories warrant further investigation.
\end{abstract}

Keywords: Endanger, morphological characters, seed germination, vegetative propagation

\section{INTRODUCTION}

Aralu (Terminalaia chebula) is a moderate deciduous tree belongs to the family combretaceae. It is a multipurpose medicinal agroforestry tree species and a popular herbal remedy in India and South East Asia. All the parts of the tree are used in traditional unani and homeopathic medicines for treating different ailments. The dried fruit is the most prominent part used in healthcare practices. Aralu is used as an appetizer, laxative agent, used to cure nervous weakness (Surya Prakash et al., 2012). It is used as a homemade remedy for asthma, sore throat, vomiting, hiccough, diarrhea, bleeding piles and ulcers (Anwesa et al., 2013). The tree is usually propagated through seeds that are hard and pale yellow. However, long time taken for

IJMFM\&AP, Vol. 7 No. 1, 2021 germination and poor germination percentage exist as major bottlenecks in seed propagation (Hossain et al., 2005). Vegetative propagation is possible through stem cuttings and by grafting (Jose and Thomas, 1998). Aralu tree is naturally distributed only in the intermediate zone in Sri Lanka. But planted trees can be seen in all other agro- climatic zones in the country (Sanjeewa et al.,2015). However this species has received a little attention by the researchers in Sri Lanka.There is no emphasis given in varietal identification and selection of plus trees for its improvement and commercial cultivation. Therefore, it is important to ascertain genetic or phenotypic variations of available Terminalia chebula populations in different regions in Sri Lanka. In order to increase 
the production and population of the tree, the total land area under cultivation and productivity should be increased. For this expansion and improvement, it is necessary to implement well-planned research, conservation strategies and vegetative propagation techniques to produce early bearing, high yielding plants. Morphological characterization of elite Jamun (Syzigium cuminii Skeels) has been practiced in India (Swamy et al., 2017), which can be used in identification of genotypes, selection and crop improvement programs. Therefore, this study was undertaken for identification of elite genotypes and standardization of vegetative propagation techniques.

\section{MATERIALS AND METHODS}

The research was conducted as two experiments. The experiment on "morphological characterization and identification of Terminalia chebula germplasm" was conducted as a field survey in Galle and Matara districts. These two districts were selected for the study because considerable extents of Terminalia chebula plants were recorded to have in these two regions. Ten plants were selected from each district. A structured questionnaire was used to gather information. Environmental characters (site topography, associated vegetation, status of sample), plant characters (height, age, trunk circumference, tree shape, growth habit, branching density, bark color), leaf characters (leaf blade length, blade width, blade shape, apex shape, blade margin, venation, petiole length), fruit characters (bearing habit, fruit shape, apex and base shape, number of ridges on fruit, diameter of fruit, fruit and seed weight) were measured during this survey. Varietal identification was done by referring to the herbarium of royal botanical garden. A cluster analysis and a two sample $t$ test was carried out by considering all the observations (Minitab version 16). The experiment on "selection of suitable vegetative propagation method" was conducted in medicinal plant garden, Pinnaduwa, Galle. Wedge grafting, patch budding and air layering were practiced. One year old healthy vigorous plants of Terminalia catappa and Terminalia bellerica were used as root stocks for budding and grafting. Wedge grafting and patch budding were arranged in a factorial completely randomized design with nine replicates per each. Altogether there were 36 experimental units. Success percentages of grafted unions were observed after 28 days of grafting. Collected data on survival was analyzed using ANOVA in SAS software and treatment means were compared using DMRT. Air layering was practiced using three selected ten years old Aralu trees. Healthy, vigorous, semi hardwood, lateral and pencil thickened: about $30-40 \mathrm{~cm}$ length shoots of the trees were selected for layering. Two different types of hormones were used, as pure Indole Buteric Acid (IBA) and commercial hormone rootone $(0.03 \%$ IBA). Three concentrations of each two hormones were used as 500ppm, 700ppm, 900ppm, and a control treatment was practiced without using hormones. Altogether seven treatments per each tree were carried out in a randomized complete block design with three replicates. The bark of the shoots was removed as a ring to a 1 to $2 \mathrm{~cm}$ length. The rooting hormones were applied to the cutting surface and the treated area was wrapped with transparent 300 gauge polythene. Moist and sterilized coir dust was used as the rooting medium. The percentages of survival were taken in each two weeks interval period up to eight weeks.

\section{RESULTS AND DISCUSSION}

According to the results of the survey, almost all the samples studied were planted trees. No naturally occurring trees were observed in Galle and Matara districts. According to Sanjeewa et al. (2015) the T. chebula trees are naturally distributed only in the intermediate zone of Sri Lanka, although planted trees can be seen in all agro-climatic zones. All the tree samples studied were surrounded by other vegetation types such as Cinnamomum verum, Mangifera indica, Alstonias cholaris, Mesuaferrea, Anacardium occidentale, Cocos nucifera, Gmelina arborea, Artocarpush eterophyllus, Terminalia catappa, Caryotaurens, Syzygium samarangense, Artocarpus nobilis, and Musa spp etc. The tree shapes were varied as round, spread, open, irregular and oval. Sixty percent of the samples showed a vigorous growth habit, while $20 \%$ exhibited high and less growth habits. Majority of the tree samples exhibited higher branching density (45\%) while $30 \%$ moderate and $25 \%$ low branching densities respectively. The results of some other tree characteristics are represented in the table 1. Genotype M6 is the older Aralu tree which is 130 
Table 1: Tree characteristics of Aralu identified in Galle and Matara districts

\begin{tabular}{|c|c|c|c|c|c|c|}
\hline District & Genotype & $\begin{array}{l}\text { Tree height } \\
\text { (ft) }\end{array}$ & $\begin{array}{l}\text { Diameter at } \\
\text { base }(\mathrm{cm})\end{array}$ & $\begin{array}{c}\text { Diameter at } \\
\text { breast height }(\mathrm{cm})\end{array}$ & $\begin{array}{l}\text { Girth at base } \\
\text { (cm) }\end{array}$ & $\begin{array}{c}\text { Girth at breast } \\
\text { height }(\mathrm{cm})\end{array}$ \\
\hline \multirow[t]{10}{*}{ Galle } & G1 & 50.2 & 84.0 & 53.5 & 264.0 & 168.0 \\
\hline & G2 & 20.6 & 53.0 & 39.8 & 166.5 & 125.0 \\
\hline & G3 & 30.0 & 46.0 & 37.2 & 144.5 & 117.0 \\
\hline & G4 & 55.5 & 74.5 & 36.6 & 234.2 & 115.0 \\
\hline & G5 & 25.1 & 22.5 & 16.1 & 70.7 & 50.5 \\
\hline & G6 & 18.5 & 15.0 & 9.8 & 47.1 & 31.0 \\
\hline & G7 & 23.0 & 24.0 & 13.5 & 75.4 & 42.5 \\
\hline & G8 & 30.8 & 12.3 & 10.5 & 38.6 & 33.0 \\
\hline & G9 & 10.0 & 8.2 & 4.4 & 25.9 & 14.0 \\
\hline & G10 & 8.2 & 6.5 & 4.1 & 20.4 & 13.0 \\
\hline \multirow[t]{10}{*}{ Matara } & M1 & 30.5 & 55.4 & 30.9 & 174.2 & 97.0 \\
\hline & M2 & 45.3 & 86.0 & 64.9 & 270.2 & 204.0 \\
\hline & M3 & 50.2 & 79.6 & 68.4 & 250.2 & 215.0 \\
\hline & M4 & 55.0 & 67.5 & 45.8 & 212.1 & 144.0 \\
\hline & M5 & 60.8 & 78.2 & 53.5 & 254.9 & 168.0 \\
\hline & M6 & 50.1 & 91.0 & 73.2 & 286.0 & 230.0 \\
\hline & M7 & 40.5 & 89.8 & 71.6 & 282.3 & 225.0 \\
\hline & M8 & 25.0 & 29.2 & 25.8 & 91.9 & 81.0 \\
\hline & M9 & 24.0 & 24.3 & 25.7 & 91.5 & 82 \\
\hline & M10 & 45.0 & 85.2 & 74.8 & 210.1 & 145.0 \\
\hline Pvalue & & 0.001 & 0.000 & 0.021 & 0.003 & 0.000 \\
\hline $\begin{array}{l}\text { SD } \\
\text { (Standarc }\end{array}$ & Deviation) & 13.34 & 24.85 & 68.61 & 92.31 & 57.16 \\
\hline
\end{tabular}

Note: Measured tree characteristics for 10 plants per each district with $p$ values and SD of two sample t test significant at 0.05 level

years old. The tree exhibits the highest diameter at base $(91 \mathrm{~cm})$, diameter breast height $(73.2 \mathrm{~cm})$, higher girth at base $(286 \mathrm{~cm})$ and highest girth at breast height $(230 \mathrm{~cm})$. According to the two sample $\mathrm{t}$ - test results, the height of the trees $(\mathrm{p}=0.01)$, the diameter at base $(\mathrm{p}=0.000)$, girth at base $(\mathrm{p}=0.003)$, diameter breast height $(\mathrm{p}=0.021)$, girth at breast height $(\mathrm{p}=0.000)$ of the trees were significantly different $(p=0.05)$ from one region to the other. Based on a research conducted in different agro ecological zones in Sri Lanka, it has revealed that variations were observed in stem/trunk characters, leaf characters and fruit characters of $T$. Chebula (Sanjeewa et al., 2015).

According to the two sample $t$ test carried out for the leaf characteristics of the Aralu tree, the average leaf blade length $(p=0.1)$, average leaf blade width $(p=0.4)$, average petiole length $(p=0.4)$ of Galle and Matara districts were not significantly different. However, both between-and within-tree variations in different agro-ecological zones of Sri Lanka were significant $(\mathrm{p}<0.01)$ in terms of leaf characters (Sanjeewa et al., 2015).The highest average leaf blade length $(13.4 \mathrm{~cm})$ was recorded from Aralu tree at Nagaramaya temple in Galle. The lowest leaf blade length $(7.4 \mathrm{~cm})$ was observed from a tree at Pinnaduwa medicinal plant garden. Most of the plants in two districts have leaf blade lengths more than $8 \mathrm{~cm}$. The highest average leaf blade width was $8.4 \mathrm{~cm}$ and lowest leaf blade width of $4.1 \mathrm{~cm}$ was recorded from Nagaramaya temple and Pinnaduwa medicinal plant garden respectively. The highest leaf petiole length $(3.2 \mathrm{~cm})$ and the lowest $(0.9 \mathrm{~cm})$ reported at Nagaramaya temple and Pinnaduwa medicinal plant garden respectively. Figure 1 represents the variation of leaves in different Aralu trees in Matara district. 


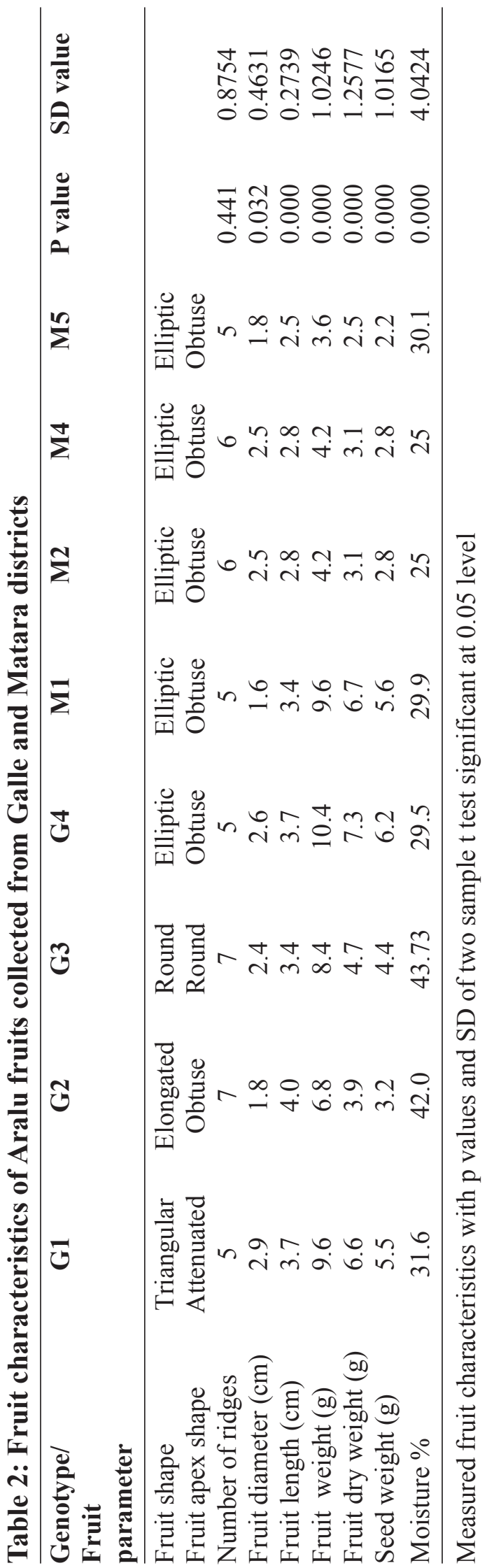

Table 3: Identified categories and genotypes

\begin{tabular}{ll}
\hline Category & Genotypes \\
\hline A & G1, M5 \\
B & G2, G3, M1 \\
C & G4, M4 \\
D & G5, G7, M8 \\
E & G6, G8, G9, G10, M9, M10 \\
F & M2, M3, M6, M7 \\
\hline
\end{tabular}

(G- Galle, M- Matara)

Fruit characteristics observed in the samples from Galle and Matara districts are represented in the table 2. There were four types of fruit shapes observed as triangular, elongate, round and elliptic. Almost all the fruit samples in Matara district were elliptic in shapes were attenuated, obtuse and round. Fruit apex shape of all the samples in Matara district were obtuse. According to the two sample $t$ test carried out, number of ridges on the fruits $(\mathrm{p}=0.441)$ was not significantly different in both regions. But average fruit diameter $(p=0.032)$, average fruit length $(p=0.000)$, average fresh fruit weight $(p=$ $0.000)$, average dry fruit weight ( $\mathrm{p}=0.000)$, average seed weight $(\mathrm{p}=0.000)$, average moisture $\%$ $(\mathrm{p}=0.000)$ in Galle and Matara districts were significantly different. According to Sanjeewa et al. (2013), the within tree variation for fruit characters was not significant ( $p>0.01)$, while the between trees was significant $(p<0.01)$ for fruit characters such as fruit shape and size. Six Aralu varieties in Galle and Matara districts were identified by the cluster analysis. Genetic variability is key prerequisite in any breeding programmes for tree improvement (Navhale et al., 2011). The category and the genotypes included in each category is represented in the table 3 . In the royal botanical garden, no any data were available for varietal identification of this species.

Results of the experiment of budding and grafting of $T$. chebula using different rootstocks are represented in the table 4. Significantly highest survival percentage of T.chebula $(77.7 \%)$ was recorded in wedge grafted plants using Terminalia catappa root stocks. And patch budding with Terminalia bellerica rootstock was successful at a rate of $66.6 \%$. But air layering of Aralu by using different concentrations of IBA and commercial hormone did not form roots. Only a callus formation on the layered surface was observed after eight weeks period. 


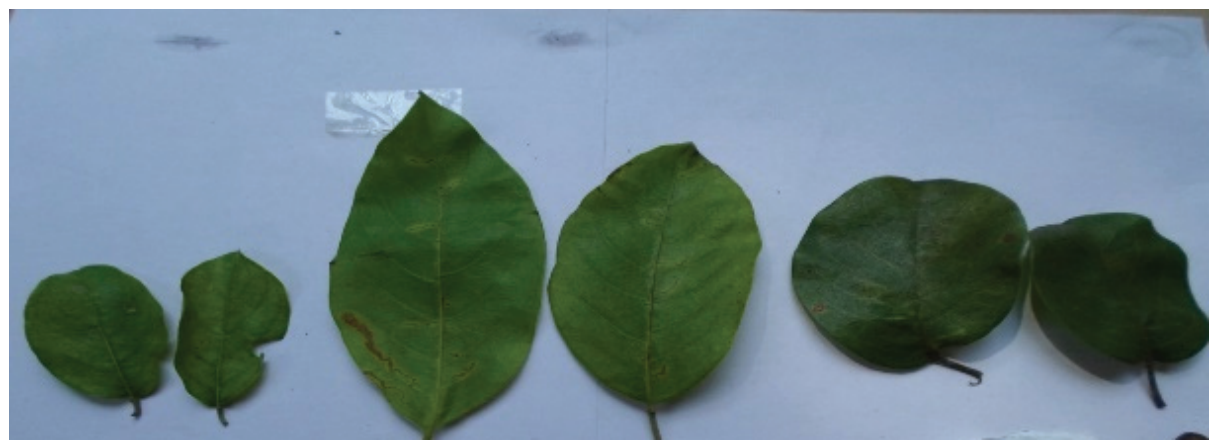

Fig. 1: Leaf variation of different trees at Matara district

Table 4: Survival percentage of Terminalia chebula at four weeks after budding and grafting

\begin{tabular}{lcccc}
\hline Treatment & PropagationType & Rootstock & Scion & Survival \% \\
\hline TCG & Wedge grafting & Terminalia catappa & Terminalia chebula & $77.7^{\mathrm{a}}$ \\
(T.catappa Grafting) & Patch budding & Terminalia catappa & Terminalia chebula & $44.4^{\mathrm{c}}$ \\
$\begin{array}{l}\text { TCB } \\
\text { (T.catappa } \text { Budding) }\end{array}$ & & & \\
$\begin{array}{l}\text { TBG } \\
\text { (T.bellerica } \text { Grafting) }\end{array}$ & Wedge grafting & Terminalia bellerica & Terminalia chebula & $33.3^{\mathrm{d}}$ \\
$\begin{array}{l}\text { TBB } \\
\text { (T.bellerica } \text { Budding) }\end{array}$ & Patch budding & Terminalia bellerica & Terminalia chebula & $66.6^{\mathrm{b}}$ \\
\hline
\end{tabular}

Means followed by the same superscripts are not significantly different at $\mathrm{p}>0.05$

\section{CONCLUSIONS}

From this present investigation, it is concluded that six categories of $T$. chebula were identified and this provide a clue for wide genetic variability of Terminalia chebula. For vegetative propagation of Terminalia chebula, rootctocks of Terminalia catappa and Terminalia bellerica were found to be suitable. Further, propagation through air layering without or with the concentrations of 500 ppm, 700 ppm, $900 \mathrm{ppm}$ of IBA and commercial hormone are not much effective in air layering of Aralu.

\section{REFERENCES :}

Anwesa, B., Subir, B.K. and Rabi, C.R. 2013. Therapeutic potential of Terminalia chebula Retz.(Combretaceae): the ayurvedic wonder, Asian Pacific Journal of Tropical Biomedicine, 3: 244-252.

Hossain, M.A., Arefin, M.K., Khan, B.M. and Rahman, M.A. 2005. Effects of seed treatments on germination and seedling growth attributes of Horitaki (Terminalia chebula Retz.) in the nursery. Research Journal of Agriculture and Biological Sciences, 1(2): 135-141.
Jose, P.A and Thomas, J. 1998. An account of the vegetative propagation in Terminalia chebula Retz, The Indian Forester, 124 (5):357-359.

Navhale, V.C, Sonone, N.G., Jangam, P.S., Jadhav, S.T and Bhave, S.G. 2011. Genetic variability and selection of candidate plus trees in chebulic myrobalan (Terminalia chebula Retz.). Electronic Journal of Plant Breeding, 2(1): 157-163.

Sanjeewa, T.A.B.D., Pushpakumara, D.K.N.G. and Sangakkara, U.R. 2013. Morphological characterization of Terminalia chebula Retz. in Sri Lanka, Tropical Agricultural Research, 25(1): 127-132.

SuryaPrakash, D.V., Sreesatya, N., Avanigadda, S. and Vangalapati, M. 2012. Pharmacological review on Terminalia chebula. International Journal of Research in Pharmaceutical and Biomedical Sciences, 3(2) : 679-83.

Swamy, G.S.K., Anushma P.L and Jagadeesha R.C. 2017. Morphological characterization of elite Jamun (Syzigium cuminii Skeels) genotypes, International Journal of Minor Fruits, Medicinal and Aromatic Plants, 3 (1): 09-15. 